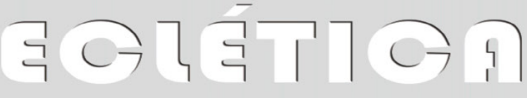

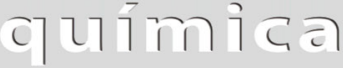

\section{COMFORMATIONAL ANALYSIS AND ELECTRONIC PROPERTIES OF FLUOROMETHYLFURAN OLIGOMERS: SEMIEMPIRICAL AND DFT STUDY.}

\author{
Banjo Semire*a, Isaiah Ajibade Adejoro ${ }^{\mathrm{b}}$ and Olusegun Abayomi Odunola*a \\ ${ }^{a}$ Department of Pure and Applied Chemistry, Ladoke Akintola University of Technology, Ogbomoso, Nigeria. \\ bepartment of Chemistry, University of Ibadan, Ibadan, Nigeria. \\ semireban@yahoo.com,odunola@yahoo.com
}

Structural and electronic properties of oligomers of fluoromethylfurans (FMFs), $\mathrm{OC}_{4} \mathrm{H}_{4}-\mathrm{CH}_{\mathrm{n}} \mathrm{F}_{3-\mathrm{n}}$ with $\mathrm{n}=1$, 2, 3 and 4 have been studied using ZINDO/AM1 and B3LYP/6-31G(d) basis set. Preliminary study using AM1 and ab initio $(\mathrm{HF})$ 6-31G(d) with medium basis set was carried out on di-, tri- and tetramer FMFs in order to investigate the stability of configuration of the polymer chains and conformation analysis of the dimers. There is noticeable effect of substituents on the geometries of FMFs as compared to polyfuran, polymethylfuran and chloromethylfuran (CMF) analogues [11] as well as improved characteristics as conducting polymers compared polymethylfurans and CMFs. The most stable conformation is the anti-planar conformation except in fluoromethylfuran in which antigauche conformation is most stable. The energy band gaps, electronic spectroscopy and electronic dipole moment vectors of the compounds are presented. Generally FMFs present lower energy band gaps, longer wavelength and higher electric dipole moments and are therefore more suitable as monomer for conducting polymer especially trifluoromethylfuran.

Keywords: Fluoromethylfurans, electronic properties, ZINDO and DFT.

\section{INTRODUCTION}

In particular, organic $\pi$-electron systems have received attention as potential photo- and electro active materials [1-4]. The task of materials development encompasses a suitable selection of structural units (monomers) either with charge transport property or optical properties. The fundamental requirement for all these organic materials is the ability to form stable and smooth filling either via vapour deposition or by solution coating methods. However, the electronic and optical properties of $\pi$-conjugated polymers results from a limited number of states around highest occupied and the lowest unoccupied level [5]. The task of materials development encompasses a suitable selection of structural units (monomers) either with charge transport property or optical properties. Conjugated conducting polymers have been a subject of intense experimental and theoretical studies since 1977 when this class of material was fully tested [6]. In intrinsic conducting polymers, the conductivity is assigned to the delocalization of $\pi$-bonded electrons over the polymeric backbone, exhibiting unusual electronic characteristics, such as low energy optical transitions, low ionization potentials and high electron affinities [7].

In recent years systematic efforts have been aimed at investigating the molecular and electronic structures of polymers, polyfurans inclusive and its derivatives for building photonic devices [8,9]. Polyfuran films are found to exhibit electrical and optical properties similar to those of polythiophene and polypyrrole; though its electrical conductivity is lower than the latter two polymers. The resistivity of polyfuran is found to be very sensitive to humidity and its application as a sensor of humidity is proposed [10]. Polyfurans have been used in co-polymerizing conducting polymers as gas sensors, wires, mircoactuators, antielectrostatic coating, solid electrolytic capacitors, polymeric batteries, electronic devices and functional membranes [9].

In our previous studied, we have theoretically examined the electronic properties of chloromethylfuran (CMF) oligomers. It was observed that wavelength shifted to longer wavelength with the increase in chlorine atoms [11]. Therefore, the aim of this present study is to theoretically study the structural and electronic properties of oligomers including dimer, trimer and tetramer of fluoromethylfurans (FMFs) for 
the preparation of corresponding conducting polymers with improved electrical and mechanical properties. The results will be compared with chloromethylfuran analogues (CMFs). However, conformational analysis will be carried out on FMF dimmers. The structures and the numbering scheme used for FMF monomers and their oligomers in this study are arranged in head-tail and head-tail fashion in the oligomer chain as illustrated in Figure 1.
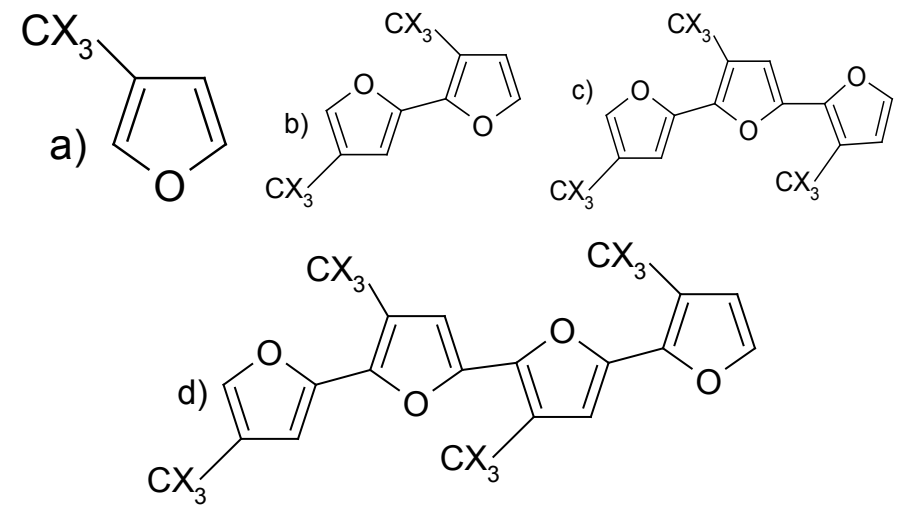

Figure 1. Structure of the FMFs monomers and their oligomers with $-\mathrm{CX}_{3}$; where $-\mathrm{CX}_{3}$ stands for $-\mathrm{CH}_{2} \mathrm{~F},-\mathrm{CHF}_{2},-\mathrm{CF}_{3}$.

\section{Methods of calculation}

Quantum chemical calculations were performed at ZINDO based on optimized geometry from AM1 implemented on hyperchem program [12] and B3LYP level of theory with $6-31 \mathrm{G}(\mathrm{d})$ basis set [13]. All the parameters were allowed to relax and all the calculations converged to an optimized geometry. The ZINDO/CIS was used for calculation of UV-spectra since it has been proved to be good enough to describe UV-spectral of organic molecules [14-16]. The conformational analysis for the neutral structures was carried out by changing the torsional angle $(\theta$, dihedral angle between central two furan rings, (O-C-C-O) by 10 steps in the opposite direction between $0^{\circ}$ (syn-planar) and $180^{\circ}$ (antiplanar). The B3LYP/6-31G* method was employed as implemented in Spartan program [17].

\section{Geometries of Fluoromethylfurans}

The connecting bond length between an adjacent pair monomer ring of an extended chain, $\mathrm{R}_{i}-\mathrm{R}_{j}$ is slightly affected by substituent groups (Table 1). Fluorine substitutions in the FMF oligomers slightly increase the $\mathrm{R}_{i}-\mathrm{R}_{j}$ with respect to the furan, methylfuran oligomers and chloromethylfuran (CMF) analogues [11]. This is due to the higher polarity of fluorine substitutions in the oligomer chains as compared to chlorine. Also, the geometrical data (Table 1) show that the $\mathrm{R}_{i}-\mathrm{R}_{j}$ bond decreases when the number of monomers increase in an oligomer chain.

The dihedral angle defining torsion between an adjacent pair ring plane of an extended chain, $\mathrm{D}_{\mathrm{R} i-}$ ${ }_{\mathrm{R} j}$ values for furan, methylfuran and $\mathrm{Fu}-\mathrm{CF}_{3}$ oligomers show that they are more planar than other FMFs and CMFs [11]. As expected of conducting polymers the distortions decrease with increase in the length of a polymer chain. Since, the planarity of polymers chain is a necessary factor for electrical conducting of polymers $[8,18,19]$. The FMFs would be more conductive as compared to corresponding CMFs [11] but less conductive than fluoromethylpyrroles due to higher $\mathrm{D}_{\mathrm{R} i-\mathrm{R} j}$ values [20]. However, the results show that the $\mathrm{Fu}-\mathrm{CF}_{3}$ oligomer would be more preferable structure for electro-polymerization synthesis of conducting polymer of furan derivatives as compared to furan and chloromethylfuran. The values of bond lengths obtained from ZINDO/AM1 are shorter than that of DFT/6$31 \mathrm{G}(\mathrm{d})$ whereas dihedral angles from ZINDO/AM1 are larger that the corresponding DFT/6-31G(d).

Table 1: Selected bond lengths $(\AA \hat{)})$ and dihedral angles $\left({ }^{\circ} \mathrm{C}\right)$ of FMF oligomers obtained at B3LYP/6-31G(d) and ZINDO/AM1 (bold) methods.

\begin{tabular}{|c|c|c|c|c|c|c|}
\hline Oligomer & $\mathrm{R}_{1}-\mathrm{R}_{2}$ & $\mathrm{R}_{2}-\mathrm{R}_{3}$ & $\mathrm{R}_{3}-\mathrm{R}_{4}$ & $\mathrm{D}_{\mathrm{R} 1-\mathrm{R} 2}$ & $\mathrm{D}_{\mathrm{R} 2-\mathrm{R} 3}$ & $\mathrm{D}_{\mathrm{R} 3-\mathrm{R} 4}$ \\
\hline *Di-Fu & $\begin{array}{c}1.4480 \\
(\mathbf{1 . 4 4 4 0})\end{array}$ & & & 0 & & \\
\hline$* \mathrm{Di}_{-\mathrm{FuCH}}$ & $\begin{array}{c}1.4482 \\
(\mathbf{1 . 4 4 4 0})\end{array}$ & & & $\begin{array}{l}0.6 \\
(\mathbf{4 . 6})\end{array}$ & & \\
\hline $\mathrm{Di}-\mathrm{FuCH}_{2} \mathrm{~F}$ & $\begin{array}{c}1.4484 \\
(\mathbf{1 . 4 4 4 0})\end{array}$ & & & $\begin{array}{c}23.4 \\
(28.2)\end{array}$ & & \\
\hline $\mathrm{Di}^{-\mathrm{FuCHF}}{ }_{2}$ & $\begin{array}{l}1.4486 \\
(\mathbf{1 . 4 4 4 2 )}\end{array}$ & & & $\begin{array}{c}24.5 \\
(\mathbf{3 0 . 4}) \\
\end{array}$ & & \\
\hline $\mathrm{Di}^{-\mathrm{FuCF}_{3}}$ & $\begin{array}{c}1.4487 \\
(\mathbf{1 . 4 4 4 2 )}\end{array}$ & & & $\begin{array}{l}-0.4 \\
(\mathbf{0 . 8})\end{array}$ & & \\
\hline *Tri-Fu & $\begin{array}{l}1.4446 \\
\text { (1.4439) }\end{array}$ & $\begin{array}{c}1.4449 \\
(\mathbf{1 . 4 4 3 9 )}\end{array}$ & & $\begin{array}{l}-0.6 \\
(\mathbf{0 . 4})\end{array}$ & $\begin{array}{c}2.0 \\
(-2.4)\end{array}$ & \\
\hline${ }^{*}$ Tri-FuCH 3 & $\begin{array}{c}1.4455 \\
(\mathbf{1 . 4 4 3 5 )} \\
\end{array}$ & $\begin{array}{c}1.4458 \\
(\mathbf{1 . 4 4 4 6 )} \\
\end{array}$ & & $\begin{array}{c}0.4 \\
(\mathbf{1 0 . 4}) \\
\end{array}$ & $\begin{array}{l}-0.5 \\
(9.8)\end{array}$ & \\
\hline Tri-FuCH ${ }_{2} \mathrm{~F}$ & $\begin{array}{c}1.4464 \\
(\mathbf{1 . 4 4 7 8 )} \\
\end{array}$ & $\begin{array}{c}1.4465 \\
(\mathbf{1 . 4 4 5 8 )} \\
\end{array}$ & & $\begin{array}{l}21.9 \\
(26.6) \\
\end{array}$ & $\begin{array}{r}24.5 \\
(\mathbf{3 1 . 2}) \\
\end{array}$ & \\
\hline Tri-FuCHF ${ }_{2}$ & $\begin{array}{c}1.4479 \\
(\mathbf{1 . 4 4 4 8 )}\end{array}$ & $\begin{array}{c}1.4478 \\
(\mathbf{1 . 4 4 4 6 )} \\
\end{array}$ & & $\begin{array}{c}22.4 \\
(\mathbf{1 6 . 8}) \\
\end{array}$ & $\begin{array}{l}25.2 \\
(\mathbf{3 0 . 4}) \\
\end{array}$ & \\
\hline Tri-FuCF 3 & $\begin{array}{c}1.4476 \\
(\mathbf{1 . 4 4 4 6 )} \\
\end{array}$ & $\begin{array}{c}1.4474 \\
(\mathbf{1 . 4 4 4 6 )} \\
\end{array}$ & & $\begin{array}{l}1.4 \\
(\mathbf{0 . 2}) \\
\end{array}$ & $\begin{array}{c}-0.3 \\
(\mathbf{6 . 8}) \\
\end{array}$ & \\
\hline *Tetra-Fu & $\begin{array}{l}1.4452 \\
(\mathbf{1 . 4 4 4 3 )} \\
\end{array}$ & $\begin{array}{l}1.4432 \\
(\mathbf{1 . 4 4 3 9}) \\
\end{array}$ & $\begin{array}{l}1.4453 \\
(\mathbf{1 . 4 4 3 9}) \\
\end{array}$ & $\begin{array}{c}0.0 \\
(-0.4)\end{array}$ & $\begin{array}{r}-0.6 \\
\mathbf{( 2 . 6 )} \\
\end{array}$ & $\begin{array}{l}0.6 \\
(\mathbf{3 . 8}) \\
\end{array}$ \\
\hline *Tetra-FuCH 3 & $\begin{array}{c}1.4455 \\
(\mathbf{1 . 4 4 4 6 )}\end{array}$ & $\begin{array}{c}1.4436 \\
(\mathbf{1 . 4 4 3 9 )}\end{array}$ & $\begin{array}{c}1.4457 \\
(\mathbf{1 . 4 4 3 9 )}\end{array}$ & $\begin{array}{c}0.0 \\
(-1.2)\end{array}$ & $\begin{array}{c}-1.4 \\
(\mathbf{0 . 8})\end{array}$ & $\begin{array}{l}-0.6 \\
(\mathbf{2 . 6})\end{array}$ \\
\hline Tetra-FuCH ${ }_{2} \mathrm{~F}$ & $\begin{array}{l}1.4432 \\
(\mathbf{1 . 4 4 4 4 )}\end{array}$ & $\begin{array}{l}1.4453 \\
(\mathbf{1 . 4 4 4 2 )}\end{array}$ & $\begin{array}{l}1.4483 \\
(\mathbf{1 . 4 4 4 1 )}\end{array}$ & $\begin{array}{c}39.1 \\
(\mathbf{5 2 . 4})\end{array}$ & $\begin{array}{c}23.4 \\
(\mathbf{3 6 . 4}) \\
\end{array}$ & $\begin{array}{c}33.7 \\
(28.2) \\
\end{array}$ \\
\hline Tetra-FuCHF ${ }_{2}$ & $\begin{array}{l}1.4474 \\
\text { (1.4449) }\end{array}$ & $\begin{array}{c}1.4456 \\
(\mathbf{1 . 4 4 4 3 )}\end{array}$ & $\begin{array}{c}1.4484 \\
(\mathbf{1 . 4 4 4 2 )}\end{array}$ & $\begin{array}{c}26.0 \\
(\mathbf{4 1 . 4})\end{array}$ & $\begin{array}{c}20.4 \\
(\mathbf{1 4 . 2})\end{array}$ & $\begin{array}{l}25.0 \\
(\mathbf{3 5 . 8})\end{array}$ \\
\hline Tetra-FuCF 3 & $\begin{array}{c}1.4472 \\
(\mathbf{1 . 4 4 4 6 )}\end{array}$ & $\begin{array}{l}1.4456 \\
(\mathbf{1 . 4 4 4 5 )}\end{array}$ & $\begin{array}{l}1.4465 \\
(\mathbf{1 . 4 4 4 3 )}\end{array}$ & $\begin{array}{l}-0.4 \\
(-5.6)\end{array}$ & $\begin{array}{l}2.6 \\
(\mathbf{8 . 2})\end{array}$ & $\begin{array}{c}0.8 \\
(\mathbf{1 0 . 4})\end{array}$ \\
\hline
\end{tabular}

$\mathrm{R}$ : bond length between an adjacent pair monomers ring of an extended chain. $\mathrm{D}_{\mathrm{Ri} \text {-Rj }}$ : dihedral angle between an adjacent pair monomers ring of an extended chain. *Data from [6] for effective comparison. 


\section{Conformational analysis}

The results of the torsion potential of the FMT dimers are presented in Figure 2. The rotational profiles obtained show the existence of the syngauche conformer for all FMF dimers (except trifluoromethylfuran) corresponding to average values of $\theta$ with $30.10^{\circ}$ (see Table 2). The rotational barrier present four extrema, three maxima situated at $0^{\circ}$, $90^{\circ}$ and $180^{\circ}$ and a minimum located at about $30.10^{\circ}$. However fluoromethylfuran has additional minimum at about $160^{\circ}$ (anti-gauche). The most significant result found with hybrid B3LYP functional is the presence of a minimum for methylfuran and 2difluoromethylfuran in the syn-gauche region corresponding to $\theta=30^{\circ}$. In fluoromethylfuran, two minima are presented; the syngauche conformer at $\theta=30^{\circ}$ and anti-gauche conformer at $\theta=160^{\circ}$ which most stable by about $1.10 \mathrm{Kcal} / \mathrm{mol}$ than syn-gauche conformer (Table 2). Generally, the most stable conformation is anti conformer.

Table 2: Relative energy (Kcal/mol) and torsional angle of fluoromethylfuran dimmers obtained at B3LYP/6-31G(d) level.

\begin{tabular}{|l|c|c|c|c|c|}
\hline Compound & Syn & Syn-gauche & Perpendicular & Anti-gauche & Anti-plane \\
\hline MF & 1.98 & $30.20^{\circ}(1.75)^{*}$ & 3.75 & 160.00 & 0.00 \\
1-FMF & 2.00 & $30.20^{\circ}(1.10)$ & 4.10 & $(0.00)$ & 0.97 \\
2.FMF & 2.42 & $30.00^{\circ}(1.15)$ & 4.55 & $\mathrm{a}$ & 0.00 \\
3-FMF & 1.09 & $\mathrm{a}$ & 4.00 & $\mathrm{a}$ & 0.00 \\
\hline
\end{tabular}

*Relative energies of syn-gauche conformers: ${ }^{a}$ No minimum or minima are found in the curves

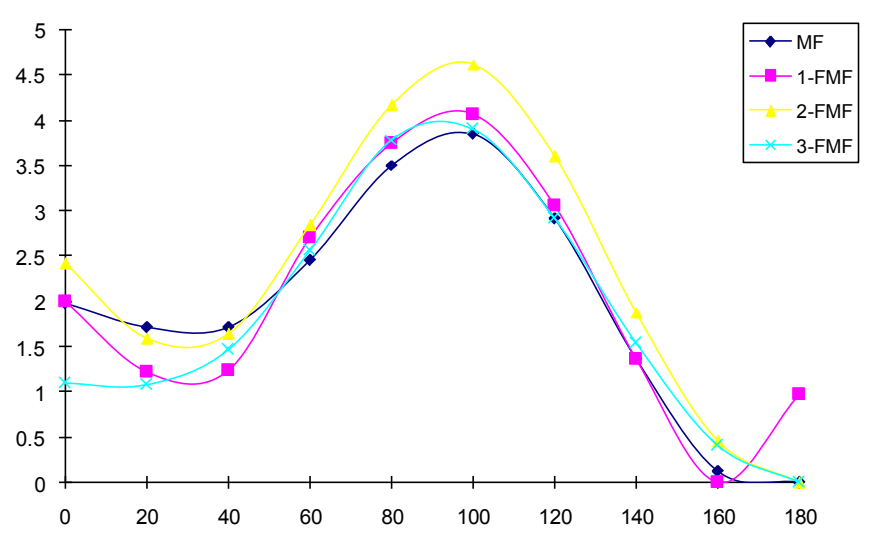

$\theta\left(^{\circ}\right)$

Figure 2: Torsion potential of fluoromethylfuran dimers obtained by B3LYP/6-31G(d) level.

The variation of inter-ring $\mathrm{C}-\mathrm{C}$ bond as a function of $\theta$ is showed in Figure 3. All curves have similar look, and the shorter interring bond corresponds to conformation planar syn and anti, indicating that this conformation holds a larger conjugation between dienic structures. As expected, the degree of conjugation changes with oligomers conformations being minimal at $\theta=90^{\circ}$ and maximal at planar conformations (antiplanar conformation, Figure 3).

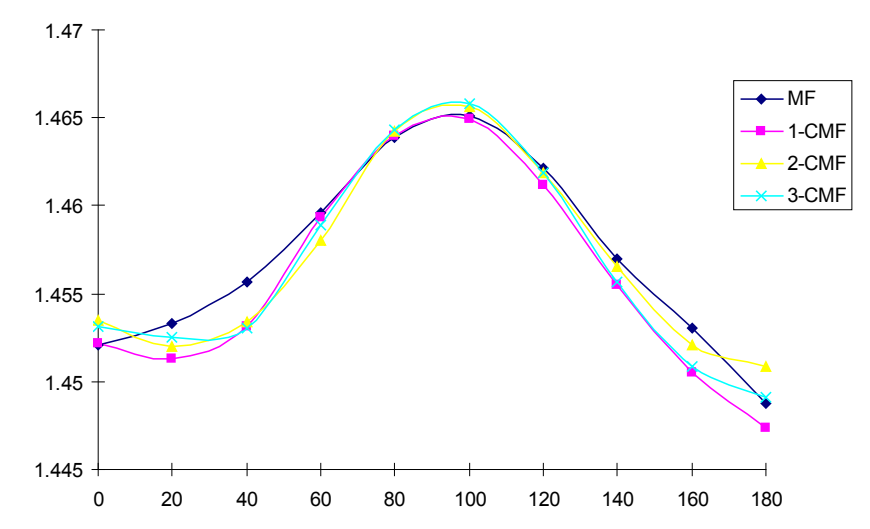

$\theta\left(^{\circ}\right)$

Figure 3: Inter-ring bond length as function of torsion angle $\theta$ for the FMF dimmers: 1-FMF is Fluoromethylfuran, 2-FMF is Difluoromethylfuran and 3-FMF is Trifluoromethylfuran.

\section{Electronic characteristics of oligomers}

It is known that energy gap between the highest occupied molecular orbital (HOMO) and the lowest unoccupied molecular orbital (LUMO), or simply HOMO-LUMO gap (HLG; $\triangle \mathrm{Eg}$ ), is a key parameter which determines the molecular admittance because it is a measure of the electron density hardness [21,22]. The HLG values of FMF oligomers, defined in Figure 4, are calculated at B3LYP/6-31G(d) level of theory. The HLG values of the furan and methylfuran monomers are lower than that of monofluoro-, difluoro- and trifluoromethylfuran monomers; however the HLG values decrease slowly with the increase in number of fluorine atoms. Therefore, it is predicted that the oligomers consisting of $\mathrm{Fu}-\mathrm{CF}_{3}$ monomer will have the highest conductivity. This is proved by comparing the trend of the HLG values of the FMF oligomers which have same number of monomers. As seen from Figure 4, the $\mathrm{HLG}$ values for the $\mathrm{Fu}-\mathrm{CF}_{3}$ tetramers are considerably lower than that of the other FMF tetramers. 


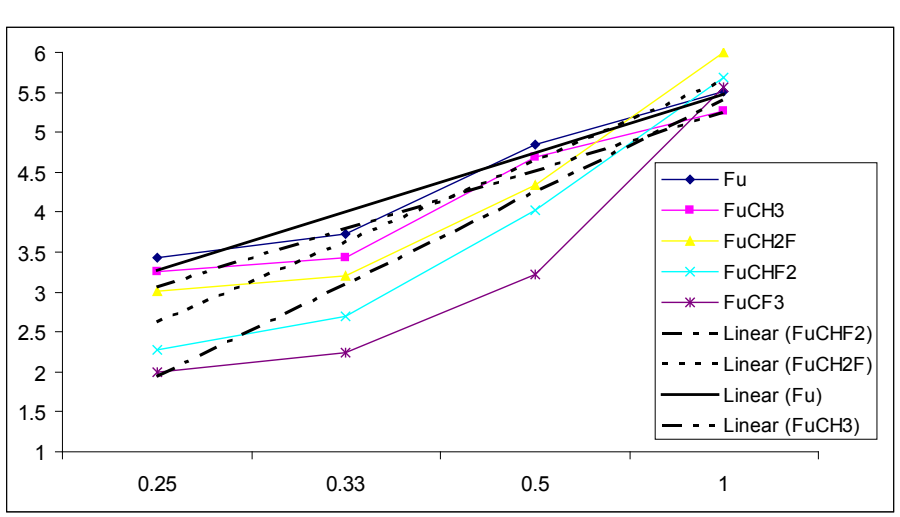

Figure 4. The HLG $\left(\Delta \mathrm{E}_{\mathrm{g}}\right)$ values obtained for all FMF oligomersB3LYP/6-31G*

\section{Dipole moments of the oligomers}

The orientation of the electric dipole moment vector $(\mathrm{m})$ of the oligomers with respect to the direction of the polymer chain determines electrochemical characteristics of the polymer on the electrode surface. In addition to their orientations, size of the electric dipole moment vector of the monomers and their interactions with the solvent and support electrolyte are the key factors in their selection for electro-polymerization. Furthermore, the structure of the electrical double layer at the surface of electrodes which determines the kinetics of the diffusion-controlled electrode reactions depends on the dipole moment of the solute molecules $[20,23]$. Thus, the calculated values of the electric dipole moment vectors for FMF monomers and their corresponding oligomers have been listed in Table 3 . The data presented in this table show that the number fluorine atoms determines the values of electric dipole moment vector. The comparative size of the dipole moment vectors for all of monomers and their oligomers with the same size follows: $\mathrm{Fu}-\mathrm{CH}_{2} \mathrm{~F}<\mathrm{Fu}-\mathrm{CHF}_{2}<\mathrm{Fu}-$ $\mathrm{CF}_{3}$

According to this trend, the oligomers consisting of $\mathrm{Fu}-\mathrm{CF}_{3}$ oligomers are expected to be more soluble in polar solvents because of the larger electric dipole moments. Also, it is observed (Table 4) that the electron donor characters of the $-\mathrm{CH}_{3}$ substituent decreases the dipole moment vector of the methylfuran oligomers, if the furan oligomers are taken as references as it was observed for fluoromethylpyrrole [20] and CMFs [11].
Table 2. The total dipole moments (in Debye, $m$ ) of the FMF monomers and their oligomers obtained with B3LYP/6-31G(d) method

$\begin{array}{cccccc} & \text { Furan } & \mathbf{F u C H}_{3} & \mathbf{F u C H}_{2} \mathbf{F} & \mathbf{F u C H F}_{2} & \mathbf{F u C F}_{3} \\ \text { Monomer } & 0.46 & 0.69 & 1.92 & 2.28 & 3.85 \\ \text { Dimer } & 0.00 & 0.12 & 1.79 & 2.48 & 2.75 \\ \text { Trimer } & 0.61 & 0.74 & 2.20 & 3.46 & 4.03 \\ \text { Tetramer } & 0.00 & 0.17 & 1.70 & 3.36 & 4.57\end{array}$

\section{$U V$-visible of the Oligomers}

The electronic spectra involving transition of valence electrons that occur in the UV-vis absorption was studied theoretically, in order to investigate the effect of fluorine substituent on oligomethylfurans. Table 5 shows some selected absorption $\lambda_{\max }$ and their oscillator strength for the oligomethylfurans. The oscillator strength values (O.S) showing the probability of the transition (corresponding to a fraction of negative charges (electrons) which accomplish the transition in question (oscillate). The electron donating effect of methyl group reduces as the number of fluorine atoms increases with increase in the chain length of the oligomers . The $\lambda_{\max }$ values for fluoro-, difluoro- and trifluoromethylfuran monomers are 172.22, 174.81 and $179.18 \mathrm{~nm}$ respectively, which are longer than the corresponding chlorine analogues [11]. This shows that the number of fluorine atoms on methylfuran affect the electronic properties of the polymer than chlorine. It is noticed that with increasing chain length of the oligomers the $\lambda_{\max }$ shift to a longer wavelength due to enlargement of p-conjugation in the systems. For example, the calculated $\lambda_{\text {max }}$ are 172.22, 324.02, 372.06 and $421.25 \mathrm{~nm}$, going from monomer, dimer, trimer to tetramer for fluoromethylfuran (Table 3). 
Table 3: The wave lengths $(\lambda)$ and oscillation strength (O.S) calculated for FMF monomers and their oligomers at ZINDO/S-CI

\begin{tabular}{|c|c|c|}
\hline Oligomer & $\lambda \mathrm{nm}$ & O. S \\
\hline $\mathrm{Fu}$ & 154.77 & 1.107 \\
\hline $\mathrm{FuCH}_{3}$ & 161.08 & 0.962 \\
\hline $\mathrm{FUCH}_{2} \mathrm{~F}$ & 172.22 & 0.899 \\
\hline $\mathrm{FuCHF}_{2}$ & 174.81 & 0.669 \\
\hline $\mathrm{FuCF}_{3}$ & 179.18 & 0.876 \\
\hline $\mathrm{Di}-\mathrm{Fu}$ & 169.82 & 1.134 \\
\hline $\mathrm{Di}^{-\mathrm{FuCH}_{3}}$ & 176.03 & 1.136 \\
\hline $\mathrm{Di}-\mathrm{FuCH}_{2} \mathrm{~F}$ & 324.02 & 0.532 \\
\hline $\mathrm{Di}^{-F u C H F}{ }_{2}$ & 335.37 & 0.662 \\
\hline $\mathrm{Di}-\mathrm{FuCF}_{3}$ & 406.42 & 0.676 \\
\hline Oligomer & $\lambda \mathrm{nm}$ & O. S \\
\hline Tri-Fu & 347.16 & 0.814 \\
\hline $\mathrm{Tri}_{-\mathrm{FuCH}_{3}}$ & 351.68 & 0.786 \\
\hline Tri-FuCH ${ }_{2} \mathrm{~F}$ & 372.06 & 0.840 \\
\hline Tri-FuCHF $_{2}$ & 391.22 & 0.698 \\
\hline $\mathrm{Tri}_{-\mathrm{FuCF}_{3}}$ & 416.76 & 0.667 \\
\hline Tetra-Fu & 374.82 & 1.075 \\
\hline Tetra-FuCH 3 & 322.33 & 0.839 \\
\hline Tetra-FuCH ${ }_{2} \mathrm{~F}$ & 421.25 & 0.653 \\
\hline Tetra-FuCHF ${ }_{2}$ & 577.89 & 0.592 \\
\hline Tetra-FuCF ${ }_{3}$ & 656.35 & 0.603 \\
\hline
\end{tabular}

\section{CONCLUSION}

The results of this study show that the FMF oligomers can be regarded as the possible candidates for the synthesis of corresponding conducting polyfuran derivatives with improved properties as compared to the polymers of chloromethylmethylfuran and methylfuran. In this series of FMF oligomers, the Py$\mathrm{CF}_{3}$ oligomers have the higher capability as building blocks for modified conducting polymers because these oligomers have higher planarity, lower HLG values and higher dipole moment vectors, which are all in favour of electro-polymerization. The most stable conformation is the anti-planar conformation except for fluoromethylfuran in which anti-gauche conformation is most stable. It is also found that the increase in the number of monomers of a FMF oligomer chain provides a better condition for modifying FMF polymers.

\section{REFERENCES}

[1] Y.H. Sung, Bull. Korean Chem. 20(1) (1999) 42.

[2] Z Lei, D.M. McCulloush, Adv. Matt. 14(12) (2002) 109 .

$++[3]$ J.H. Schon, P A. Dodabala, C.H. Baot-Kloc, O. Schanker, B. Batloge, 410189

[4] O. Kalisky, Organics for Electro-optical Applications. Business Communication, Inc GB-253 (2006).

[5] D. Sardar, Theoretical Investigation of Approaches for Obtaining Narrow Band Gaps in Conducting Polymers, M.Sc Thesis, Bikent University, Turkey. (2004).

[6] H. Shirakawa, E.J. Louis, A.G. Mac-Diarmid, C.K. Chiang, C.K. Heeger, J. Am Chem. Soc. Chem. Commun. (1977) 578.

[7] S. Sadki, P. Scottland, N. Brodie, G. Sabouraud, Chem. Soc. Rev. 29 (2000) 283.

[8] T. Scotheim, Handbook of Conducting Polymers, Dekker M. New York. 2nd ed. 1998, p. 993

[9] J.L. Bredas, R.R. Chance, Conjugaed polymeric materials: Opportunities in electronic, Optoelectronics and Molecular electronics. Kluver, Academic Publishers, London, 2001.

[10] T. Ohsawa, K Kaneto, K. Yoshino. J. Appl. Phys. 23 (1984) 126.

$+++[11]$ B. Semire, O.A. Odunola, Oriental J. Chem. 25 (2009) .

[12] HyperChem 8.0 preoffesional, Gainesville, Florida, USA 2008.

[13] D. Becke, J. Chem. Phys. 98 (1993) 5648.

[14] P. J. Banuelos, A. F. Lopez, M. V. Martinez, L. T. Arbeloa, A. I. Lopez, Phys. Chem. Chem. Phys., 6(17) (2004) 4247.

[15] P. J. Banuelos, A. F. Lopez, M. V. Martinez, L. T. Arbeloa, A. I. Lopez,

Chem. Phys. 296 (2004) 13.

[16] Y.J. Yang, Y.H. Kan, Z.M, Su, L. Zhao, J. Mol.

Struct. (THEOCHEM), 725 (2005) 127.

[17] Spartan 06, Wavefunction, Irvine, USA, 2007.

[18] R.J. Waltman, A.F. Diaz, J. Bargon, J. Phys. Chem. 88 (1984) 4343.

[19] W. Su, J.O. Iron, Synth. Met. 95 (1998) 159.

[20] H. Nikoofard, H. Sabzyan. J. Fluorine Chem. 128(6) (2007) 668

[21] R.G. Parr, R.G. Pearson, J. Am. Chem. Soc. 105 (1983) 7512.

[22] C.-G. Zhan, J.A. Nichols, D.A. Dixon, J. Phys.

Chem. A 107 (2003) 4184.

[23] W.H. Meyer, H. Kiess, B. Binggeli, E. Meier, G.

Harbeke, Synth. Met. 10 (1985) 255. 